\title{
Thermal Soak Analysis of Earth Entry Vehicles
}

\author{
Parul Agrawal ${ }^{1}$ and Steven A. Sepka ${ }^{2}$ \\ ERC Inc., C/O NASA Ames Moffett Field, CA, 94035 \\ Jose F. Aliaga ${ }^{3}$ and Ethiraj Venkatapathy ${ }^{4}$ \\ NASA Ames Research Center, Moffett Field, CA, USA 94035 \\ and \\ Jamshid A. Samareh ${ }^{5}$ \\ NASA Langley Research Center, Hampton, VA 23681
}

The Multi-Mission Earth Entry Vehicle project is developing an integrated tool called "Multi Mission System Analysis for Planetary Entry Descent and Landing" that will provide key technology solutions including mass sizing, aerodynamics, aerothermodynamics, and thermal and structural analysis for any given sample return mission. Thermal soak analysis and temperature predictions of various components including the payload container of the entry vehicle are part of the solution that this tool will offer to mission designers. The present paper focuses on the thermal soak analysis of an entry vehicle design based on the Mars Sample Return entry vehicle geometry and discusses a technical approach to develop parametric models for thermal soak analysis that will be integrated into the tool.

\section{Nomenclature}

$\begin{array}{ll}\text { ACC } & =\text { advanced carbon-carbon } \\ \text { CAD } & =\text { computer aided design } \\ \text { CFD } & =\text { computational fluid dynamics } \\ \text { EDL } & =\text { entry descent and landing } \\ \text { EEV } & =\text { Earth entry vehicles } \\ \text { FE } & =\text { finite element } \\ \text { FEA } & =\text { finite element analysis } \\ \text { FIAT } & =\text { fully implicit ablation and thermal response } \\ \text { MMEEV } & \text { multi mission earth entry vehicles } \\ \text { MSAPE } & =\text { multi mission system analysis for planetary entry } \\ \text { MSR } & =\text { Mars sample return } \\ \text { PICA } & =\text { phenolic impregnated carbon ablator } \\ \text { TPS } & =\text { thermal protection system }\end{array}$

\section{Introduction}

Sample return missions have occurred at various times during the history of spaceflights. These missions include Senesis, Stardust, Hayabusa, and Mars Samples Return that is planned for near future. For each of these missions the samples from the target destination (an outer planet like Mars or a comet) is returned to earth by means of an earth entry vehicle. During the entry into the earth atmosphere the vehicle is subjected to severe thermal and

\footnotetext{
${ }^{1}$ Senior Research Scientist, Thermal Protection Materials Branch, MS 234-1, NASA Ames Research Center, AIAA Sr. Member.

${ }^{2}$ Senior Research Scientist, Thermal Protection Materials Branch, MS 234-1, NASA Ames Research Center, Member.

${ }^{3}$ Research Graduate Co-op, Aerothermodynamics Branch, MS 234-1, NASA Ames Research Center.

${ }^{4}$ Chief Technologist, Entry Systems and Technologies Division, NASA ARC, MS 229-3, Moffett Field, CA 94035, AIAA Associate Fellow

${ }^{5}$ Senior Research Engineer, Vehicle Analysis Branch, MS E401, NASA Langley Research Center, AIAA Associate Fellow.
} 
mechanical loading due to aerothermal heating and impact landing on earth. Figure 1 shows the schematic of different phases of the entry vehicle. The survival of the entry vehicle and successful payload recovery are key to the success of sample return missions. In order to protect the vehicles from atmospheric heating, a layer of ablative and/or insulative Thermal Protection System (TPS) materials is used at the fore and aft body. The relatively lower conductivity of thermal protection materials causes a slow absorption of thermal energy into the interior of these vehicles. In addition low density porous foams are used surrounding the payload container to absorb the energy during the impact landing. Therefore, it could take several minutes to hours before the internal substructure and payload of the vehicle start to show a rise in temperature. Thermal soak analysis becomes very important to predict the survivability of the payload as the recovery process could take several hours. ${ }^{1}$

Researchers at NASA are working to create a common design and system analysis tool, Multi Mission System Analysis for Planetary Entry Decent and Landing (MSAPE) for Earth Entry Vehicles (EEV) that would provide design parameters, trajectory, aerothermal heating estimates, and materials recommendations to build a vehicle for any given mission. ${ }^{2,3}$ MSAPE will have a modular architecture with several different modules such as parametric vehicle geometry, structural and TPS sizing, impact dynamics, and a thermal soak model. This paper focuses on the development of a thermal soak model for this tool.

The MSAPE platform is based on elements the from Mars Sample Return (MSR) design. MSR is designed to be one of the most reliable space vehicles ever developed, due to planetary protection concerns. Therefore, it provides a logical foundation that individual missions can build upon in optimizing an EEV design to meet their specific needs. ${ }^{4}$ Figure 2 shows the basic MSR EEV design concept which is the baseline for the development of various MSAPE modules that includes a thermal soak model. A preliminary thermal analysis of MSR entry vehicle was performed by researchers at NASA Langley, which included predictions of payload temperature. ${ }^{5}$ The present work has a broader objective; while the design foundation is based on MSR, the end results will be a thermal soak module that could be used for other mission architectures as well. The spatially and time varying aerothermal environments on both fore body and aft body are applied to the present model as boundary condition resulting in accurate representation of thermal energy input. In the future, for high fidelity thermal soak models, the ablation, when necessary and prominent, will be accounted for in the model by coupling the temperature maps from the thermal response model, FIAT, ${ }^{6}$ to the finite element model. A more closely coupled scheme between the thermal response codes and commercial Finite Element (FE) software is described in Reference 7. This approach will be investigated for final point designs for missions like MSR and other sample return missions. The next section describes in detail the components, materials and finite element modeling approach for thermal soak model development.

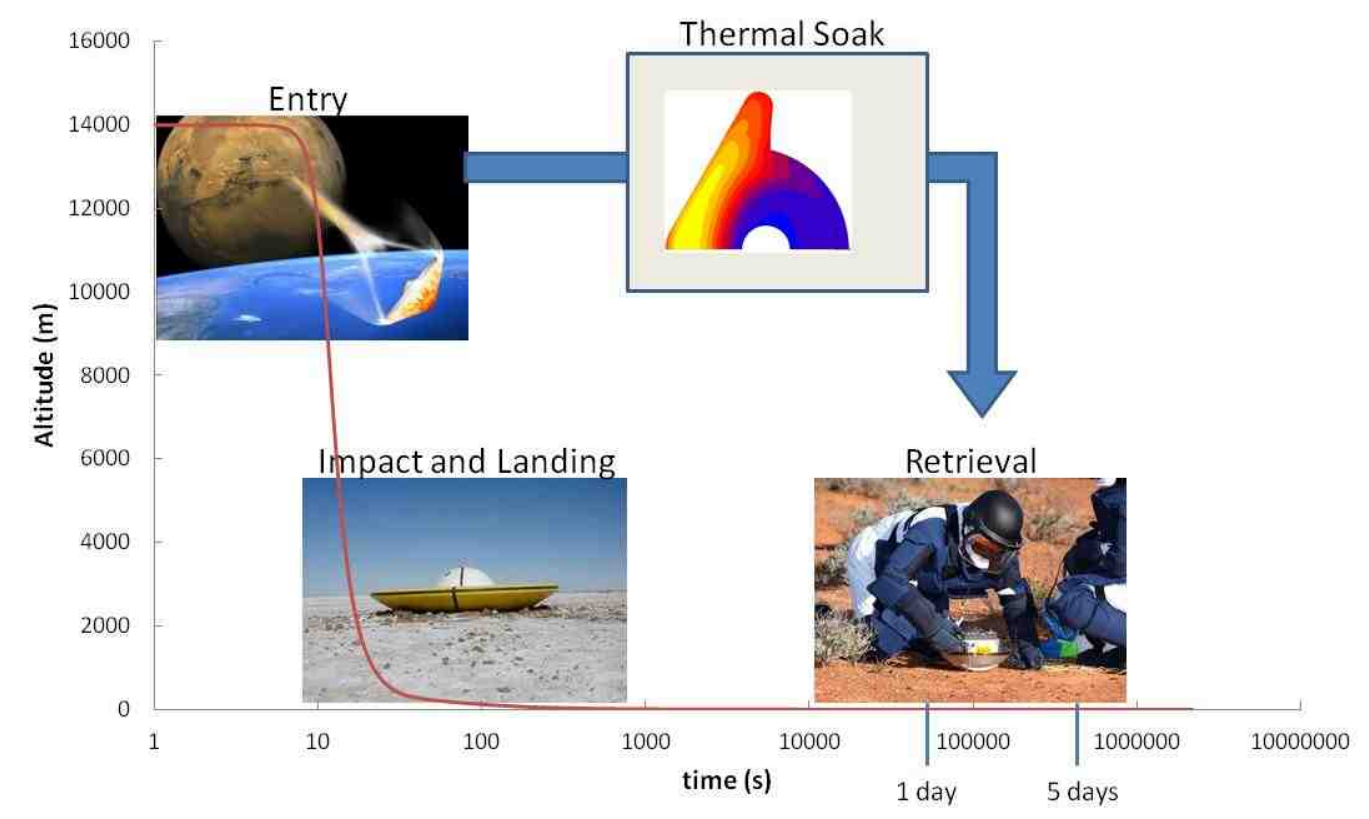

Figure 1. Different phases of earth entry vehicle and time span for thermal soak inside the vehicle. 


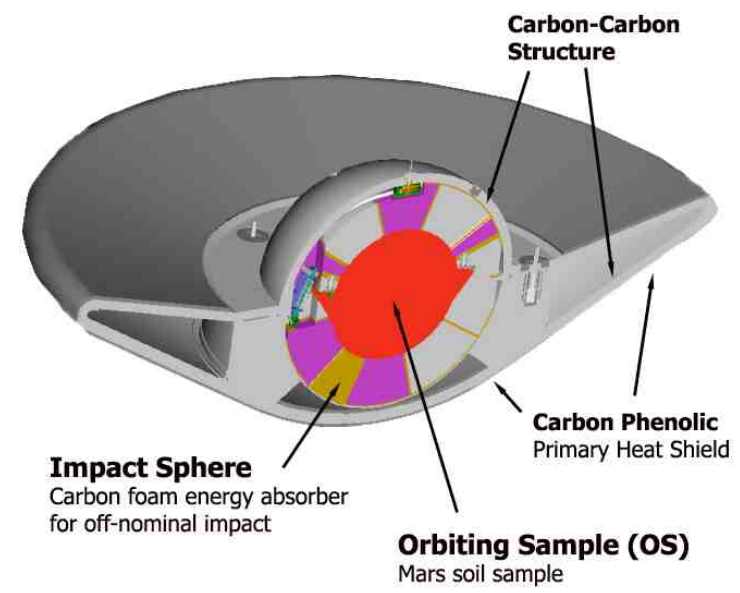

Figure 2. Mars Sample Return entry vehicle baseline design.

\section{Finite Element Model Development}

To conduct finite element modeling, the CAD geometry of the vehicle design that was developed for the MSAPE tool was imported into a commercial finite element software package, Marc-Mentat, developed by MSC corporation. ${ }^{8}$ MSC.Marc supports fully transient, non-linear, thermal Finite Element Analysis (FEA). It includes an integrated user interface, Mentat, for pre- and post-processing. A two dimensional cross section of the geometry that was developed for simple parametric MMEEV model is shown in Figure 3. The overall nominal diameter of the vehicle including the TPS material is $1.05 \mathrm{~m}$. The various sub-components of the vehicle and their thickness along the centerline vertical position are listed in Table 1.

The FE model was created based on this simplified MMEEV geometry and assumed to be 2-D axi-symmetric for several reasons. It takes the solver significantly less time to analyze an axi-symmetric geometry compared to a three dimensional geometry, which could be very time efficient when conducting thermal soak analysis for a wide spectrum of trajectories and sensitivity analyses for various parameters. In addition, it is significantly easier to impose the thermal boundary conditions like heat-flux distribution from 2-D axi-symmetric Computation Fluid Dynamics (CFD) models and temperature distribution from thermal response models.

The model was meshed in such a way that each of the main sub-components was represented as a separate element set. These sets include forward and aft-TPS, substructures, impact and body foam, wing and lid insulation, impact shell, and payload. The inclusion of various element sets will allow for flexibility in implementing different sets of materials properties when needed, shape changes after impact etc. The model was meshed using linear quad elements as shown in Figure 4. The average element size was about $1.8 \mathrm{~mm}$ which led to total 51,200 elements and 51,700 nodes.

The payload was assumed to be kept inside a hollow aluminum container. At this time the focus of the thermal soak analysis is to provide the temperature history of the payload container and the impact foam so that it can meet the thermal requirements of sample return missions. The thermal management of the payload is outside the scope of the present study.

In order to perform the first set of analyses the following materials were considered:

1) Carbon phenolic for forebody TPS

2) Phenolic Impregnated Carbon Ablator (PICA) for aft TPS

3) Advanced carbon-carbon for substructure as well impact shell

4) Rohacell for all the foams and insulations

5) Aluminum $6061 \mathrm{~T} 6$ alloy for payload container

The materials map of the FE model is shown in Figure 5. Temperature-dependent thermal properties were considered for each of the materials. The TPS and substructure materials were assumed to be transverse isotropic with thickness along the $\mathrm{x}$-axis as shown in Figure 5. The material properties for the first three thermal protection materials on the list were obtained from Configuration Managed (CM) database developed during the time of the Crew Exploration Vehicle (CEV) TPS advanced development program. ${ }^{9,10}$ The properties for Rohacell foam were obtained from communications with the manufacturer and Langley Research Center. These properties are listed in the Appendix. Aluminum 6061 values for the payload container were obtained from the MIL handbook. ${ }^{11}$ 
The heat flux values derived from CFD were input as surface boundary condition for the model. The next section provides a detailed discussion on aerothermal environment for various trajectories. Thermal conduction, surface re-radiation to ambient environment, and internal cavity re-radiation were considered as prime heat transfer mechanisms, and ablation was not modeled at this time. The heating due to applied heat flux during re-entry as well as thermal soak during the cool down period after re-entry were analyzed. An adaptive time step based on the change in temperature was used for the solver to make the computations more efficient. One of the major events after re-entry is the touchdown, when the entry vehicle is subjected to severe impact that causes significant deformation and compression of impact foams. The foam compression causes an increase in density which in turn changes the thermal properties of the foam. The touchdown and impact event would also cause changes in thermal pathways. For the present set of analyses, the changes to the model caused by impact have been ignored. However, in the future studies the analysis will be performed in two steps: 1) re-entry and time elapsed before impact and 2) cooling after impact. The geometric changes due to impact will be incorporated thorough significant mesh deformation, while the temperatures will be assumed to stay stable. The temperature distribution from the last time step of first analysis will be imposed as initial condition for the second analysis, and thermal soak will carry on.

Table 1. Thickness of the subcomponents along the vertical centerline for MMEEV vehicle.

\begin{tabular}{|c|c|}
\hline Component & Thickness (m) \\
\hline payload & 0.1684 \\
\hline forbody tps & 0.0402 \\
\hline aft tps & 0.01 \\
\hline fwd carrier structure & 0.0068 \\
\hline aft carrier structure & 0.0055 \\
\hline primary structure & 0.0081 \\
\hline impact shell & 0.002 \\
\hline impact foam & 0.1767 \\
\hline body foam & 0.0275 \\
\hline lid insulation & 0.0583 \\
\hline wing insulation & 0.0759 \\
\hline
\end{tabular}




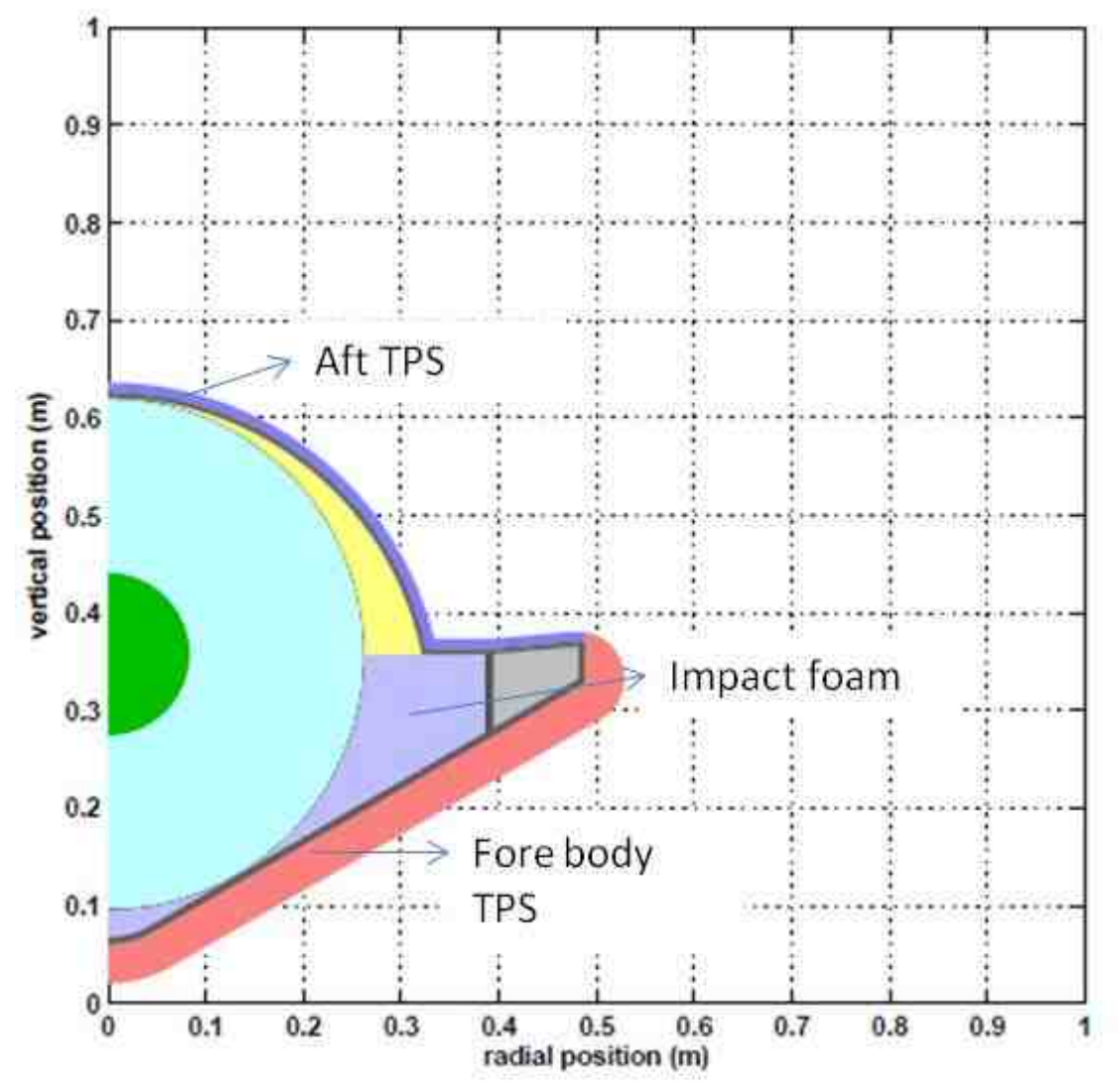

Figure 3. MMEEV thermal soak model geometry.

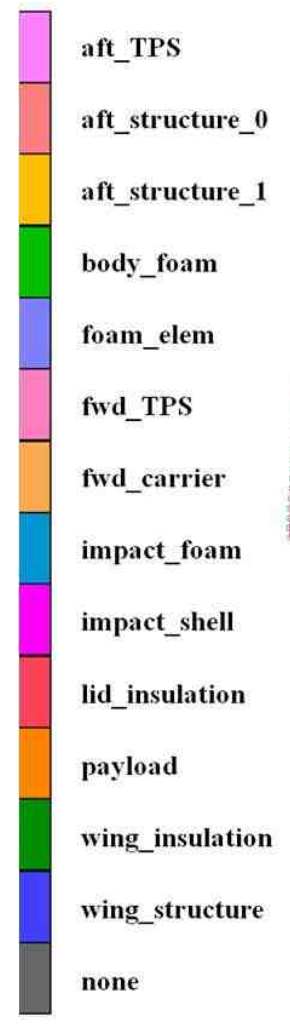

Figure 4. Finite element mesh with component sets.

5

American Institute of Aeronautics and Astronautics 


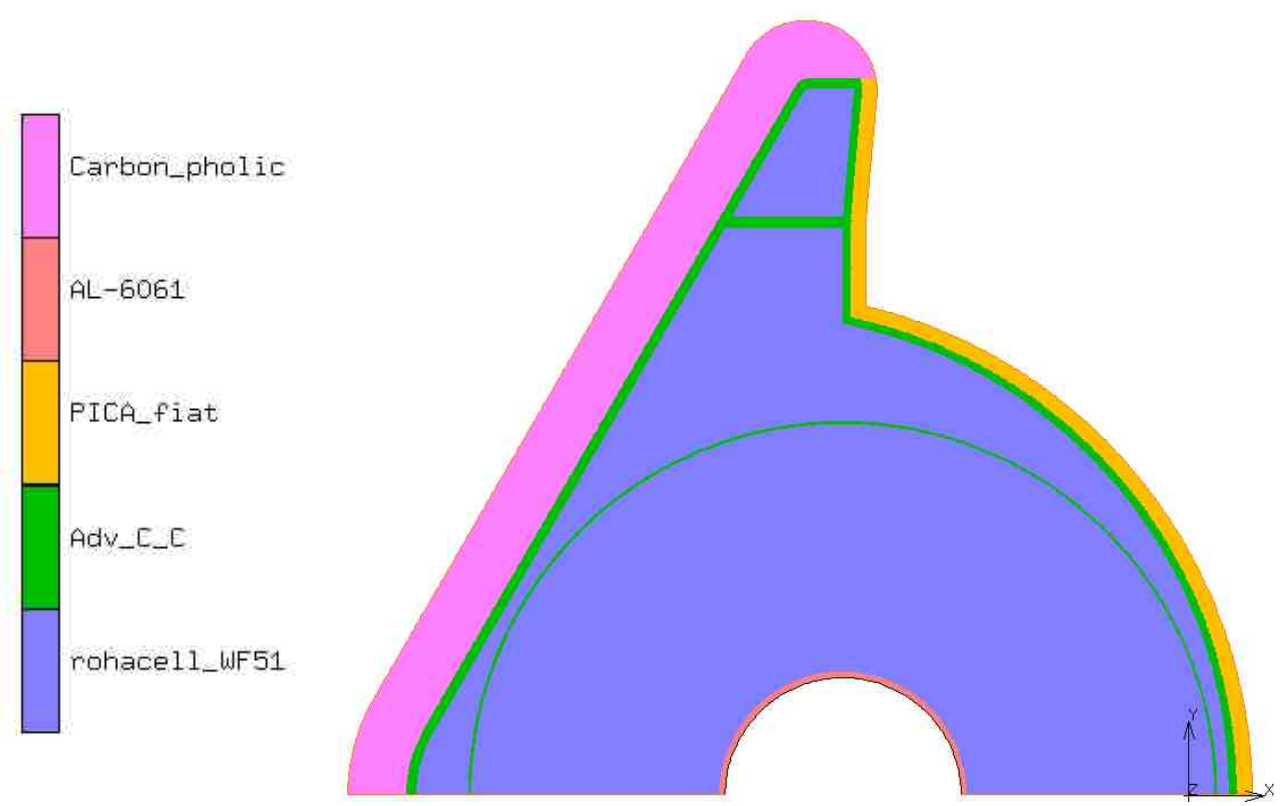

Figure 5. Materials map for the baseline thermal analysis.

\section{Entry Environments and Boundary Conditions}

The entry environment for the MMEEV program encompasses a fairly large mission trade space that includes entry velocities ranging from $10-16 \mathrm{~km} / \mathrm{s}$, ballistic coefficients of $42-129 \mathrm{~kg} / \mathrm{m}^{2}$, and entry flight path angles ranging from $-5 \mathrm{deg}$ to $-25 \mathrm{deg}$. These translate to a wide spectrum of trajectories, heatloads, and peak heat fluxes. One of the main objectives for thermal soak analyses is to be able to identify the important parameters and to develop correlation coefficients so that, for a given heat-load and trajectory, one can estimate the peak payload temperature, the time to arrive at peak temperature, and the temperature histories of the interior components of the vehicle such as the impact foam and payload. For the first set of analyses a nominal trajectory for MSR with a very high heat-load at the nose stagnation point was considered. Subsequently a trajectory space consisting of over 2700 cases was created from which a representative set of trajectories for the thermal soak analyses were selected based on statistical average and standard deviation. These trajectories have flight path angles ranging from 10 to 25 degrees and entry velocities of 10 to $14 \mathrm{~km} / \mathrm{s}$. Figure 6 shows the representative trajectory space, where maximum heat flux at the nose stagnation point of the probe is plotted against the corresponding heat load for each trajectory. The high heat load, nominal MSR trajectory is also included in this plot. The representative trajectories selected for FE thermal soak analyses and development of parametric soak models are shown in green. The trajectories selected for detailed analyses and discussions in the present paper are the highest heat load and the low heat load trajectories. These trajectories are circled in Figure 6.

The flow field was computed using the CFD code $\operatorname{DPLR}^{12}$ (v. 2.02.2), to generate spatially and temporally varying heat-flux values during the entry. The surface of the vehicle was modeled using the radiative equilibrium boundary condition with a constant emissivity of 0.85 . The flow for the present moment was assumed laminar for the entire time span of the trajectories and was modeled using an 11-species finite-rate air chemistry model. The MMEEV geometry was represented as a two-dimensional axi-symmetric body. The surface of the vehicle was made up of 256 body points. Figure 7 shows the surface of the vehicle and every tenth body point plotted along the surface. The body point "zero" corresponds to the nose stagnation point of the vehicle where the highest heating occurs. The incoming flow is from left to right. Generally two or three grid adaptations were conducted for each simulation to align the grid with the bow shock. Figure 8 shows the resulting flow field at peak heating for one of the cases. The figure also shows the Mach contours and streamlines. Ten to eleven time steps were chosen for each trajectory to capture the shape of the heat pulse. The Sutton-Graves correlation for stagnation heating was used as a guideline to choose the times steps for the CFD simulations. The CFD stagnation point heat flux solutions are plotted against the Sutton-Graves correlation in Figure 9. For the low heat load trajectory, times earlier than 8.5 
seconds (the first CFD point) are in the free-molecular regime, and a stable CFD solution could not be obtained. The trajectory time steps chosen for the high heat load trajectory span a greater distance along the heat pulse due to the nature of the flow. The heat flux distribution at peak heating along the vehicle for both the trajectories are plotted in Figure 10. For the high heat load trajectory, peak heating occurred between 60 and 70 seconds. The highest CFD value obtained was close to $1000 \mathrm{~W} / \mathrm{cm}^{2}$ at 66 seconds. For the low heat load trajectory peak heating of $692 \mathrm{~W} / \mathrm{cm}^{2}$ occurred at 10.5 seconds.

The full time history of the aerothermal environment was obtained by curve fitting the CFD solutions. The interpolation function is a power-law fit using free stream velocity and density as the independent variables. In this manner a continuous time-history was obtained for each body point along the vehicle. In Figure 11 the heat flux distributions of ten discrete CFD solutions is plotted against both body location and time for the low heat load trajectory (red circles). These are the solutions which are interpolated in time. The curve fits make it possible to estimate the integrated heat load at all 256 locations along the vehicle. The integrated heat load for the stagnation point was $38,000 \mathrm{~J} / \mathrm{cm}^{2}$ and $3000 \mathrm{~J} / \mathrm{cm}^{2}$ for the high and low heat load trajectories respectively. The FE software had in-built subroutine to apply the discrete heat flux values on 256 body points on the full outer mold line of the probe.

The spatially and temporally varying heat flux values for the trajectories were used as a surface boundary condition for the FE model. Several three dimensional data tables were generated to apply the heat flux values as a boundary condition to the model. The next section describes the thermal modeling and results from the analyses from selected high and low heat load trajectories.

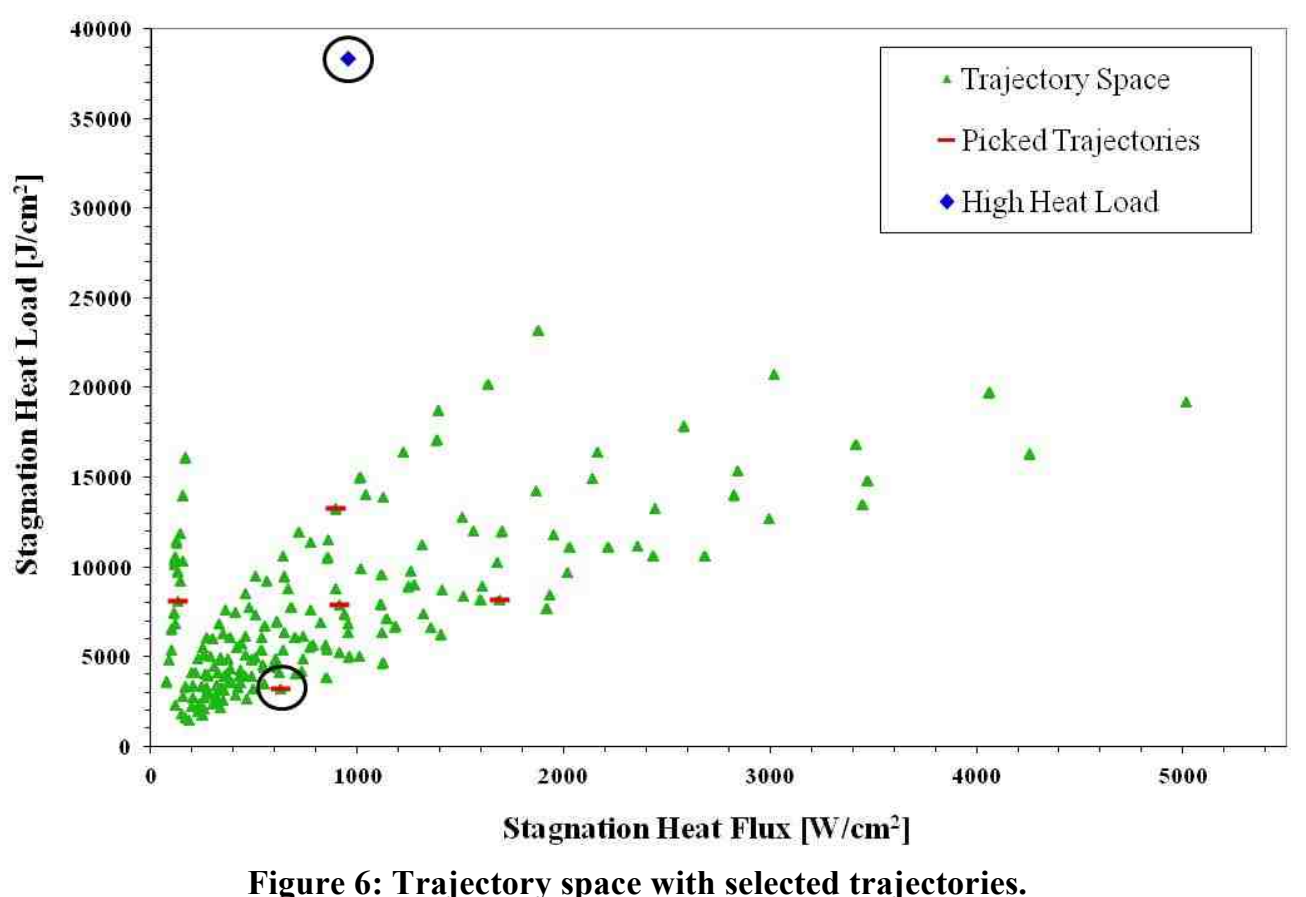

Figure 6: Trajectory space with selected trajectories. 


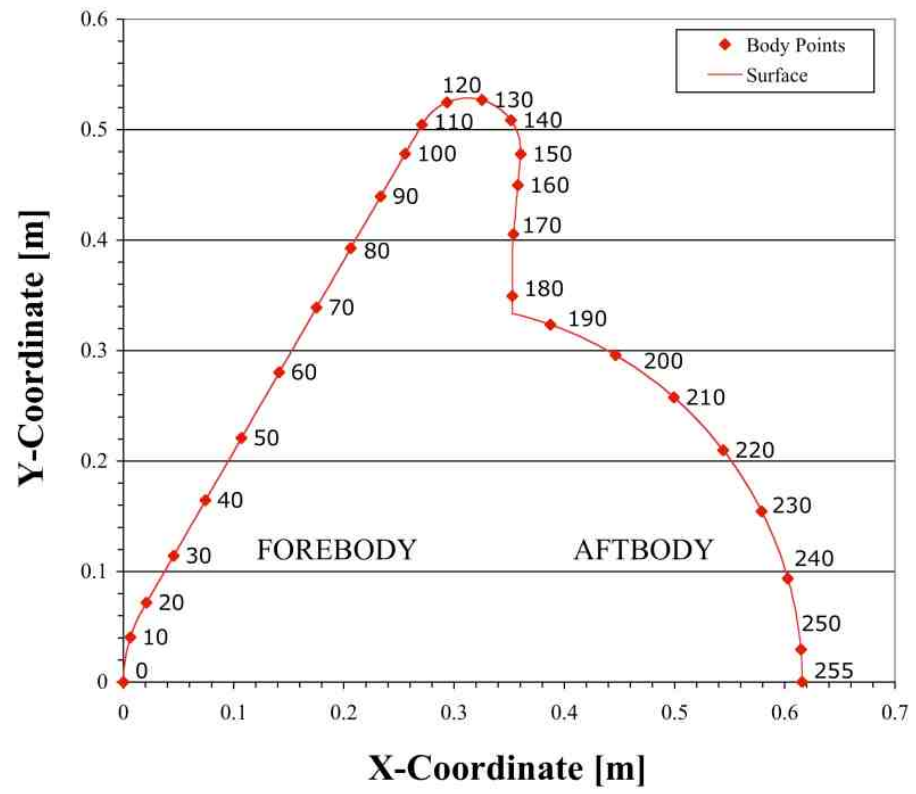

Figure 7. The 256 surface body points for full body aerothermal analysis.

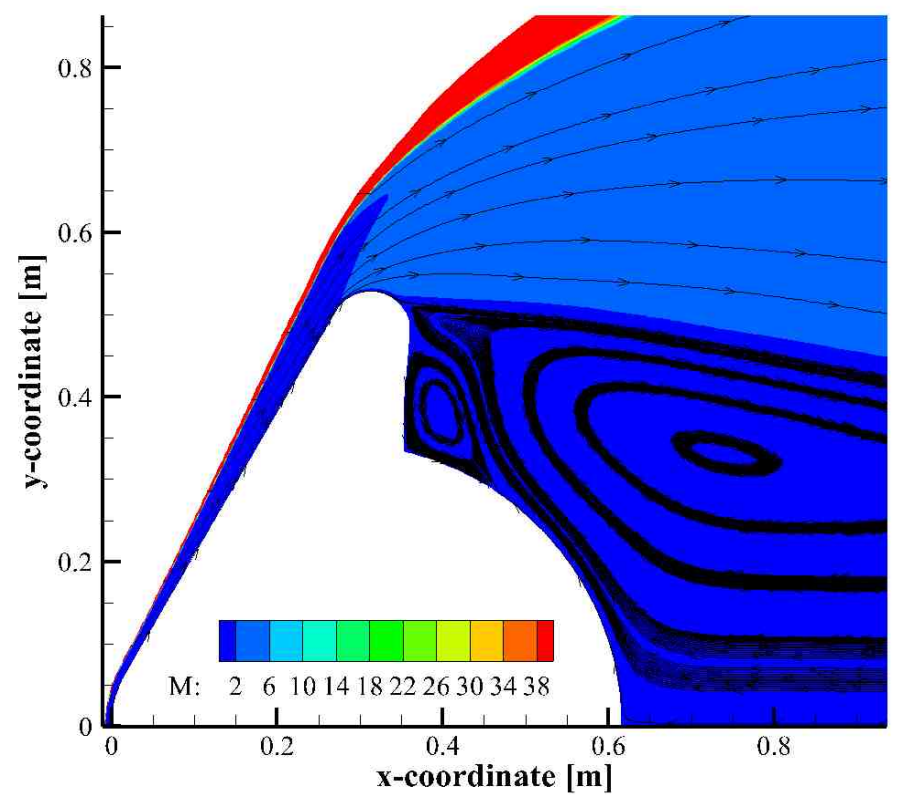

Figure 8. Mach contour and streamlines for peak heating after grid alignment. 


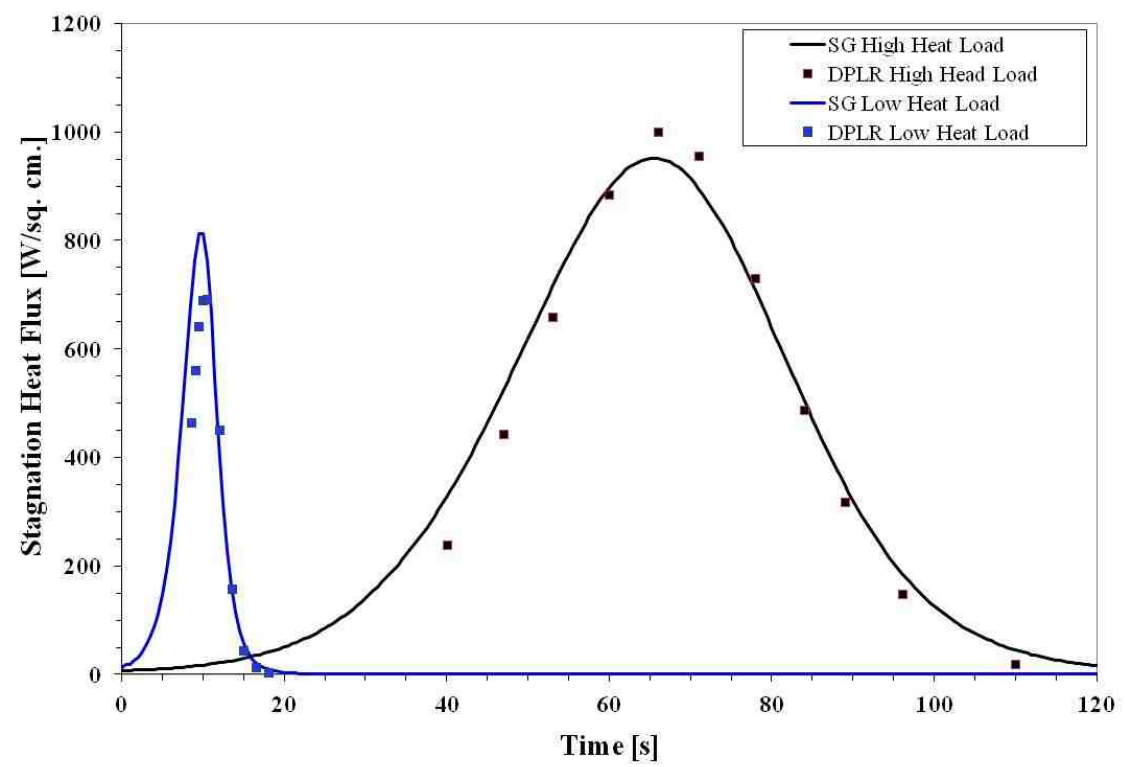

Figure 9. Sutton-Graves correlation vs. DPLR solutions for stagnation point heat flux.

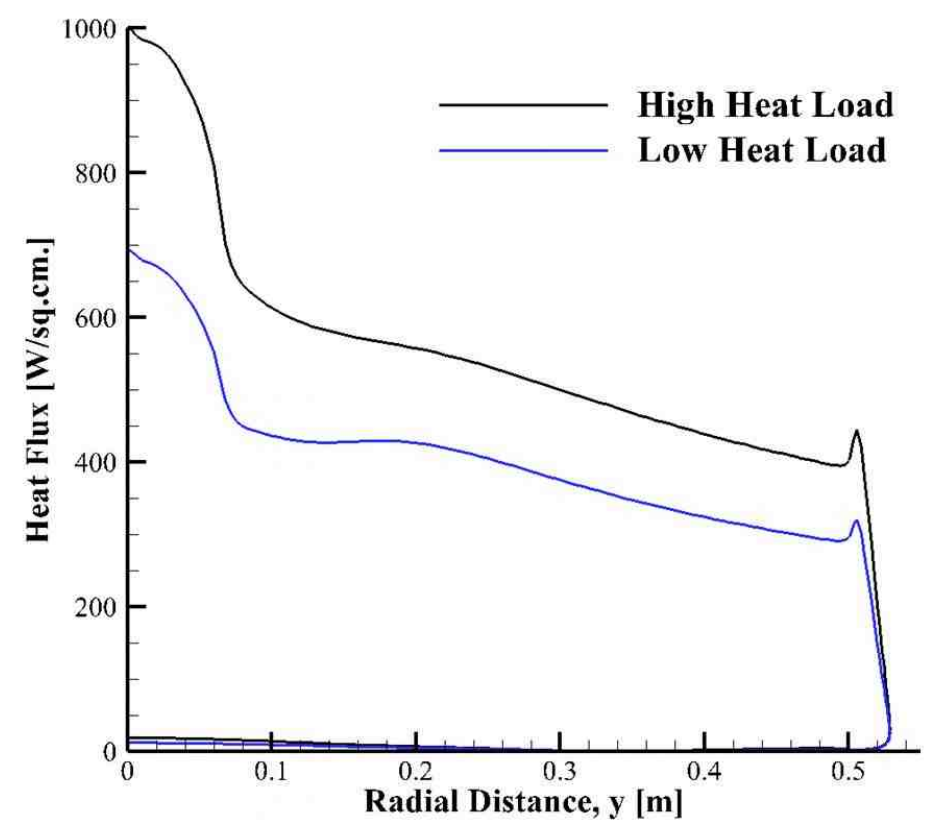

Figure 10. Heat flux distribution along vehicle at peak heating. 


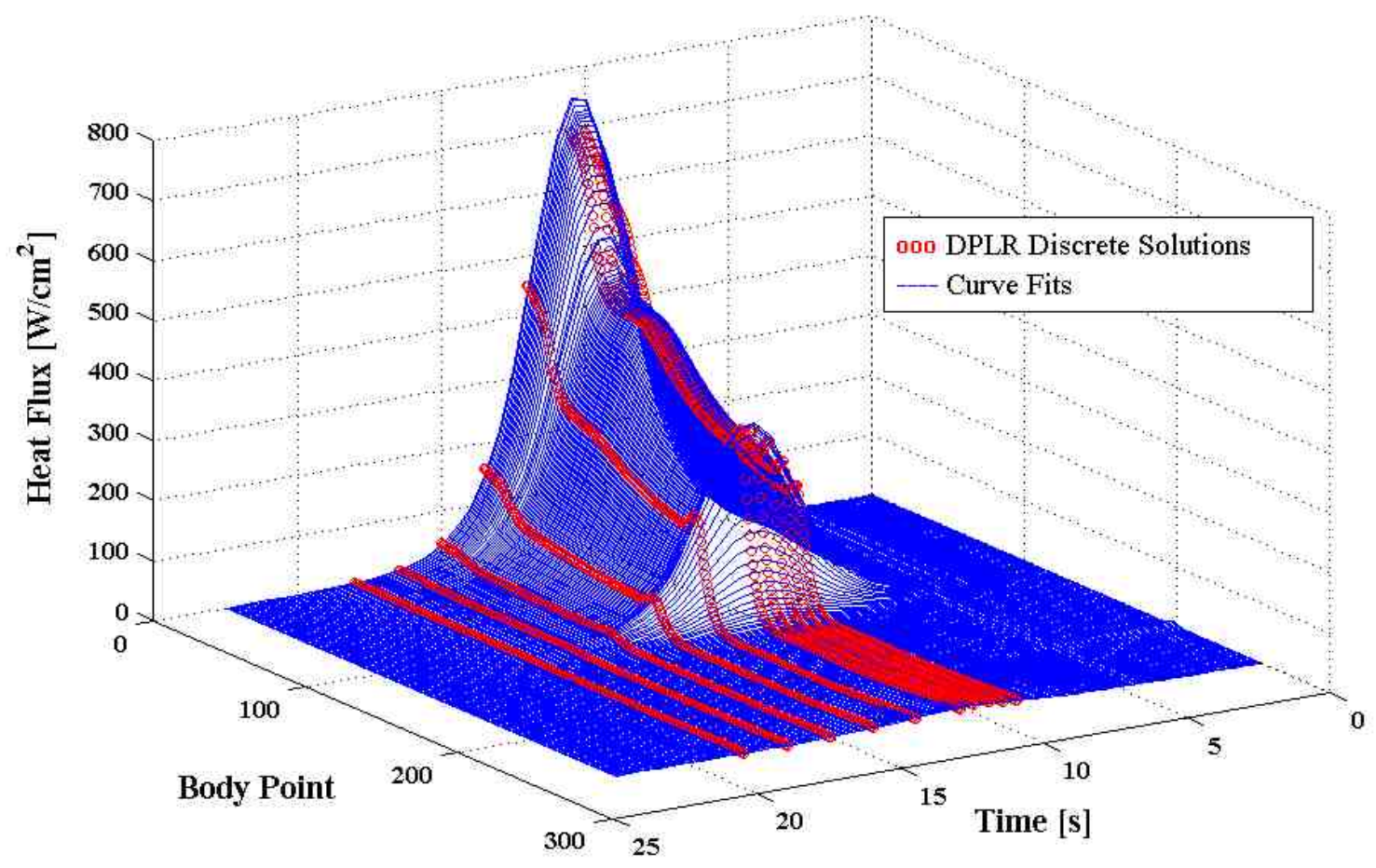

Figure 11. DPLR solutions with the curve fits super-imposed for the low heat load trajectory.

\section{Temperature Predictions in Entry Vehicle Design}

Transient thermal analyses were performed with two dimensional axi-symmetric elements. The initial and ambient temperatures were assumed to be $290 \mathrm{~K}\left(17^{\circ} \mathrm{C}\right)$. The initial temperature is an important parameter and simulations will be performed in future to investigate the effects of initial temperature. The outer surface was modeled to be re-radiating to a sink temperature of $290 \mathrm{~K}\left(17^{\circ} \mathrm{C}\right)$ during the entry and cool-down periods. The start time for analysis coincided with atmospheric entry. During re-entry the vehicle experiences a very steep temperature gradient on the forebody due to high heat flux. Figure 12 shows the temperature contours on the vehicle at the end of the heat pulse during the re-entry and right before the touchdown to the ground. While the surface temperatures are very high exceeding, $1000^{\circ} \mathrm{C}$ during re-entry and exceeding $700^{\circ} \mathrm{C}$ during touch down on the fore body TPS, the interior of the vehicle (including the body foam and payload container) remains at the room temperature. Thermal analysis on the identical vehicle configuration (with same TPS thickness) was also performed for the low heat load trajectory discussed in previous section. Figure 13 shows the temperature contour plot at the end of the heat pulse and right before touchdown for this trajectory. As expected the in-depth temperature rise in the forebody TPS is significantly smaller compared to the high heat load trajectory, and a large portion of TPS and all of the interior stay at room temperature during the re-entry. The touchdown time (when altitude is close to zero) for this trajectory occurs at 2000 seconds, and by that time the whole vehicle shows temperature below $250^{\circ} \mathrm{C}$.

Thermal soak is slow due to low conductivity of the impact and body foam, and the interiors take several hours to show a temperature rise. Figure 14 shows the temperature contours after several hours for both trajectories. For the high heat load trajectory, the body foam shows a temperature rise of $200^{\circ} \mathrm{C}$, and the payload container reaches above $50^{\circ} \mathrm{C}$ after several hours. In contrast, for the low heat load trajectory the body and impact foams stay under $120^{\circ} \mathrm{C}$ and payload container stays below $25^{\circ} \mathrm{C}$.

The peak foam temperature comparisons are shown in Figure 15. For the high heat load trajectory the peak foam temperature reaches $300^{\circ} \mathrm{C}$. Whereas for the low heat load trajectory, the foam temperature stays below $100^{\circ} \mathrm{C}$ through the entire thermal soak period. One point to be noted here is that these analyses don't consider the foam compression due to ground impact. These numbers may increase to a higher value if the foam compression is taken 
into account. FE models that would include foam compression after impact are proposed as a future MMEEV task that will be performed after the parametric studies with the present configuration.

The present simulations were performed for 45 hours of cool-down period as the payload recovery operations could take more than a day. The temperature rise in the payload container is shown in Figure 16. For the low heat load trajectory the payload container temperature stays below $25^{\circ} \mathrm{C}$. This meets the science requirements of keeping the payload below $25^{\circ} \mathrm{C}$. In contrast, the payload temperature for high heat load trajectory eventually rises beyond $50^{\circ} \mathrm{C}$ that could cause concerns if the payload recovery is not fast. These analyses lead to conclusion that while a thicker forebody TPS may seem very conservative for re-entry heating, it may be required to protect the interiors and payload from rising to very high temperature during the cool down period. Alternatively, a different architecture such as dual-layer TPS approach may be needed. The peak payload temperatures for various trajectories with different peak heat flux magnitude and stagnation point heat load are also shown in Figure 16. The data suggests that heat load magnitude is one of the key contributors for payload temperature rise, and while selecting among different trajectory it may be useful to keep in mind that a trajectory with lower heat load value can be more desirable from thermal soak perspective even if it meant a higher stagnation point heat flux value. The next section describes some of the analyses that are being performed to generate a parametric thermal soak model for MSAPE.
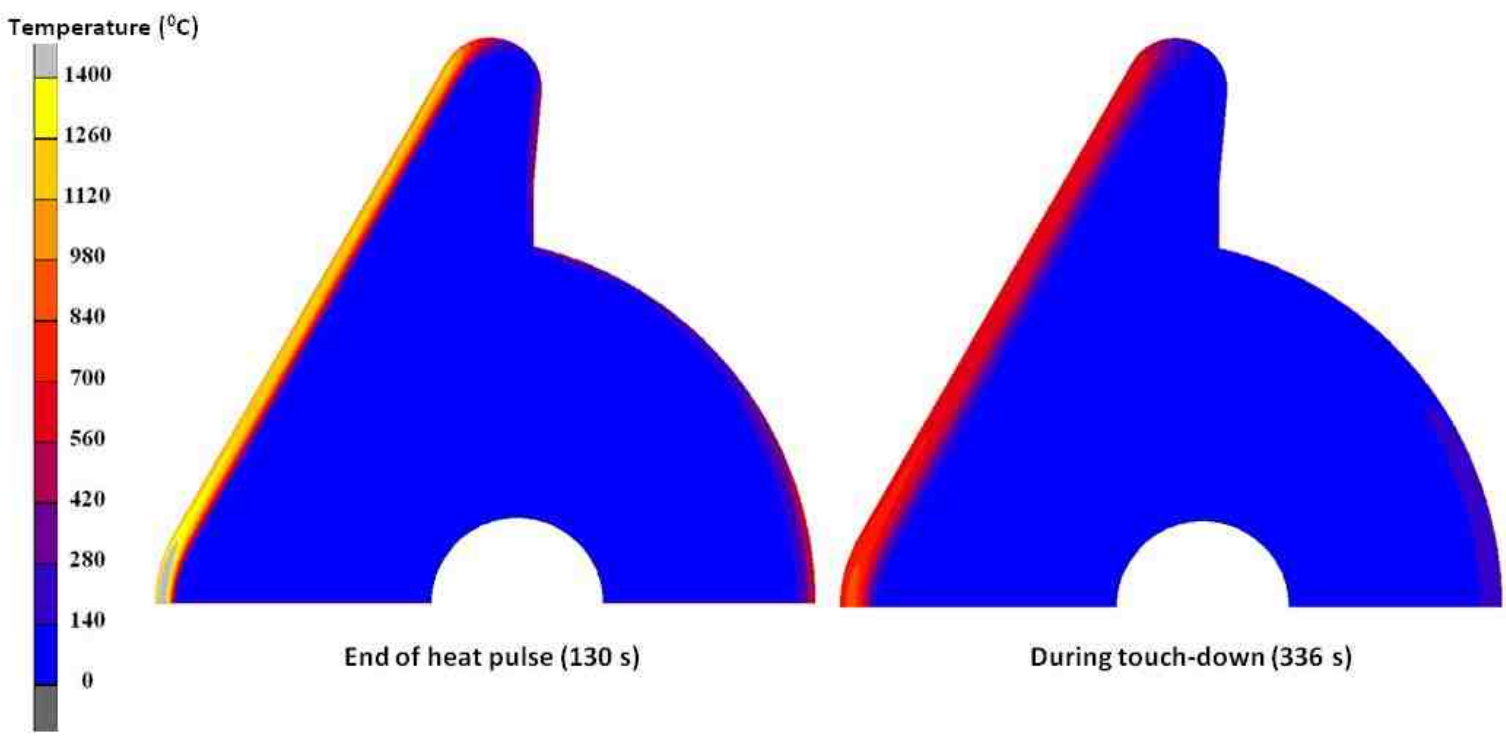

Figure 12. Temperature contours for the high heat load trajectory.
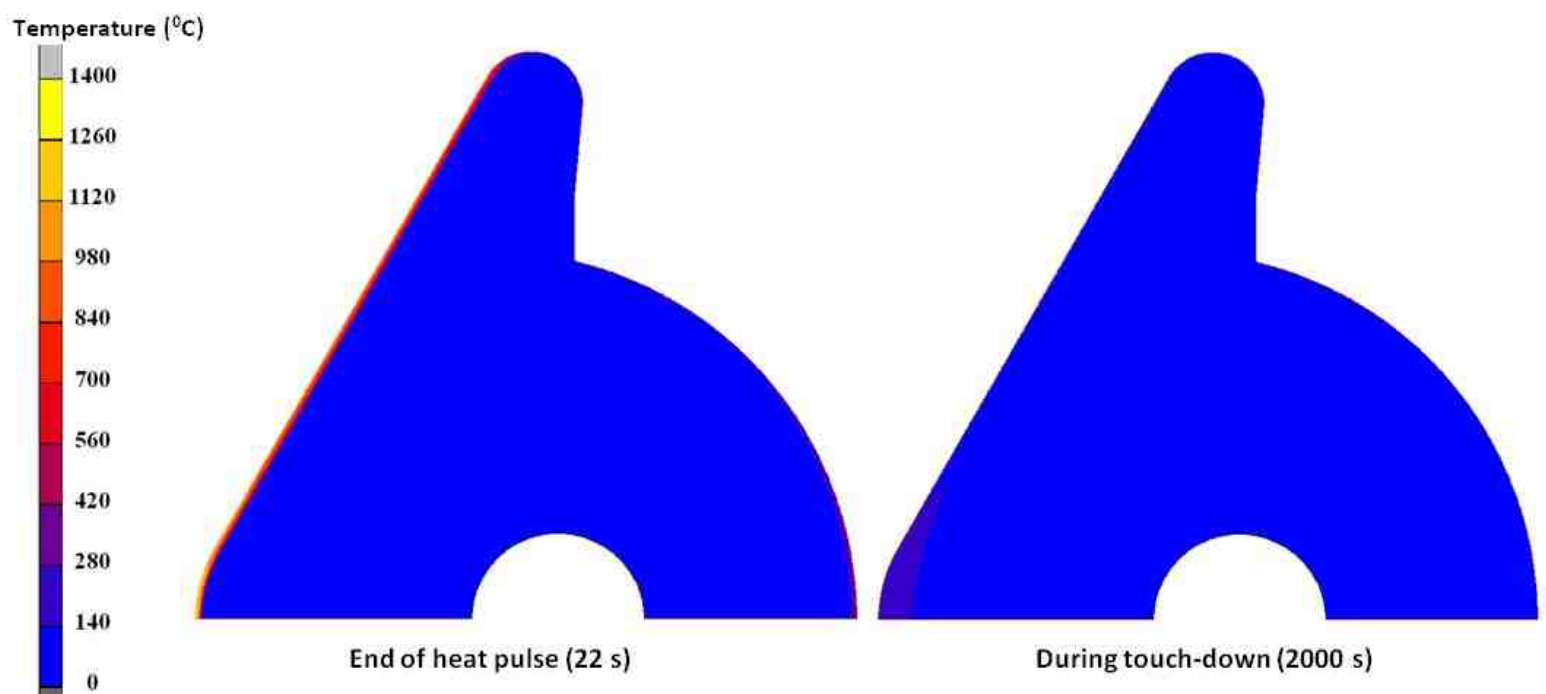

Figure 13. Temperature contours for the low heat load trajectory. 


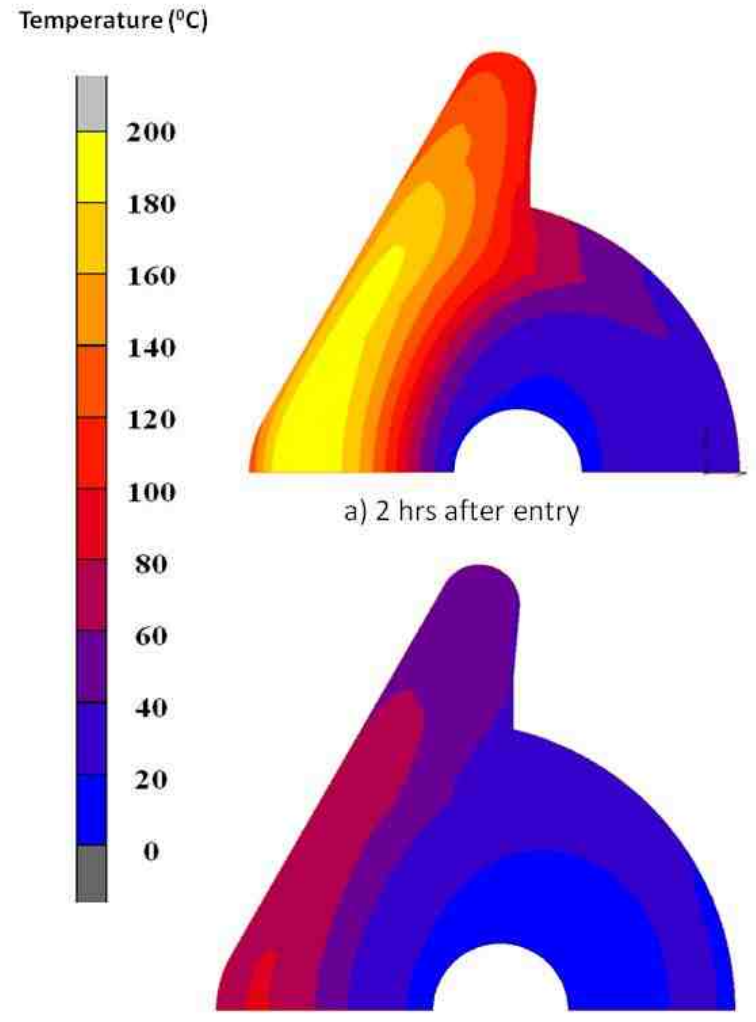

c) 2 hrs after entry

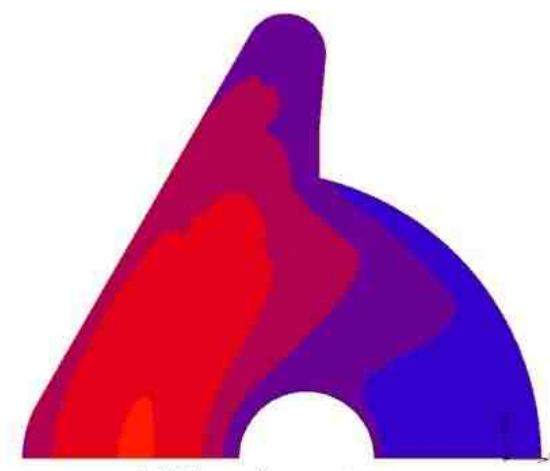

b) 5 hrs after entry

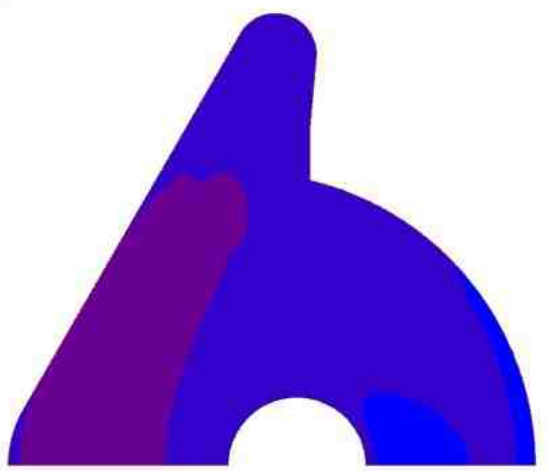

b) 5 hrs after entry

Figure 14. Temperature contours in the probe after the touchdown. Fig. 14a and 14b correspond to the high heat load trajectory; Fig. 14c and 14d correspond to the low heat load trajectory.

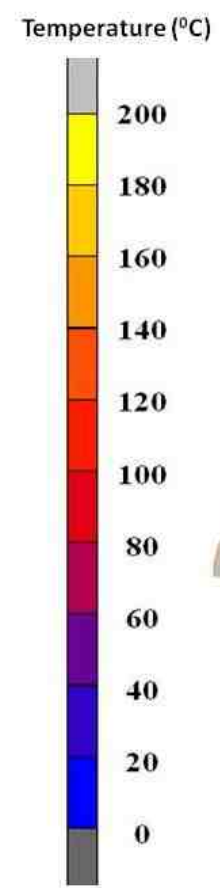

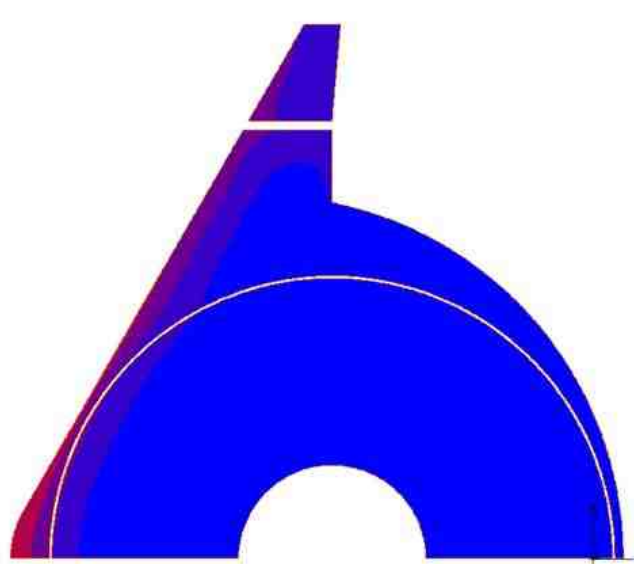

Low heat load trajectory

High heat load trajectory

Figure 15. Peak foam temperature for the two trajectories. 

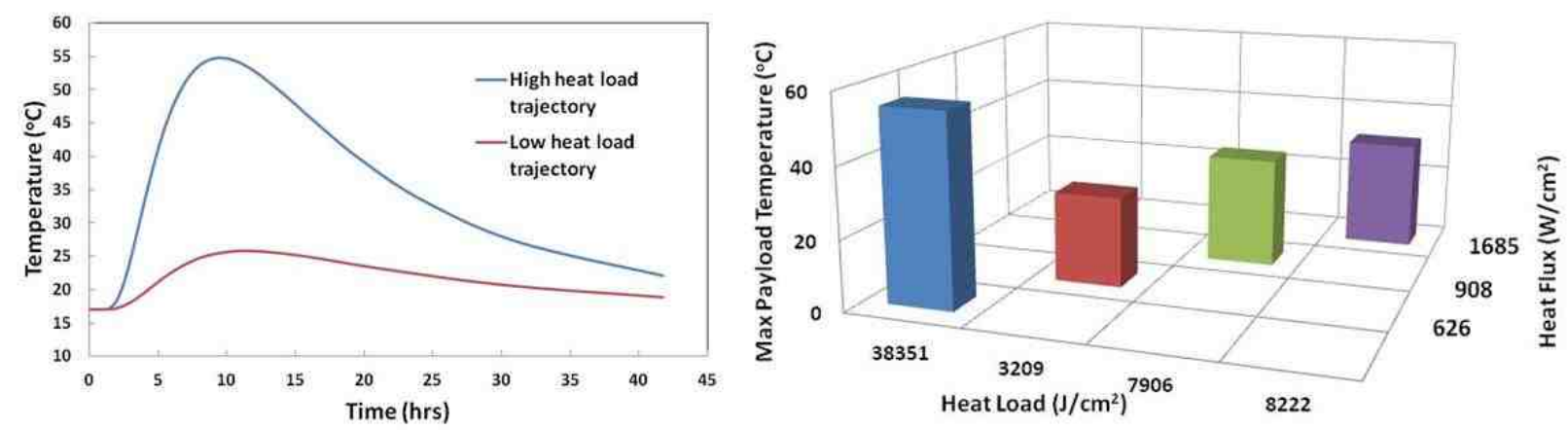

Figure 16. Payload temperature history and peak payload temperature for various trajectories.

\section{Parametric Thermal Soak Model Development for MSAPE}

One of the goals for FE thermal analysis is to identify key factors that affect the peak payload and foam temperatures and to develop simple correlation coefficients based on these factors that could lead to a parametric thermal soak model for MSAPE. To accomplish this objective several parametric studies are being performed for the five selected trajectories (mentioned in Section III) by varying heat flux magnitude, vehicle diameter TPS materials etc. This section describes some of those analyses.

The results from parametric studies for both the high and low heat load trajectories are shown in Figure 17 and 18 respectively. The heat flux was varied by scaling the magnitude throughout the surface for the entire heating cycle for the high heat load and the low heat load trajectories. The magnitudes were scaled between $0.25(25 \%)$ to $1.5(150 \%)$ times the nominal heat flux values for the trajectory. In both the cases the peak payload container temperature rises as the heat flux magnitude is increased. For the heat flux range considered for parametric models a linear relationship between the scaled heat flux magnitude and peak payload container temperature can be established for both the trajectories as shown in Figures $17 \mathrm{~b}$ and $18 \mathrm{~b}$. The influence of change in vehicle diameter is shown in Figure 19 for the low heat load trajectory. To perform these parametric studies the whole vehicle (FE model) was scaled to a smaller or larger number while the input heat flux magnitude was kept constant. Although heat flux distributions will change with size, they were not considered at this time. It turned out for a smaller diameter vehicle the peak payload temperature was significantly higher compared to a larger diameter vehicle. This could be very useful for determining the vehicle geometry for a given mission requirement.

One preliminary study for high heat load trajectory was conducted by changing the forebody material from carbon phenolic to PICA. The data suggests that choice of TPS material could significantly influence the peak temperature for payload due to the differences in material and thermal properties, and in this case the peak payload temperature was lower for PICA as shown in Figure 20. In both the cases the ablation was not considered which will affect these numbers. However, for parametric analysis and comparative studies this provides a useful insight to mission designers.
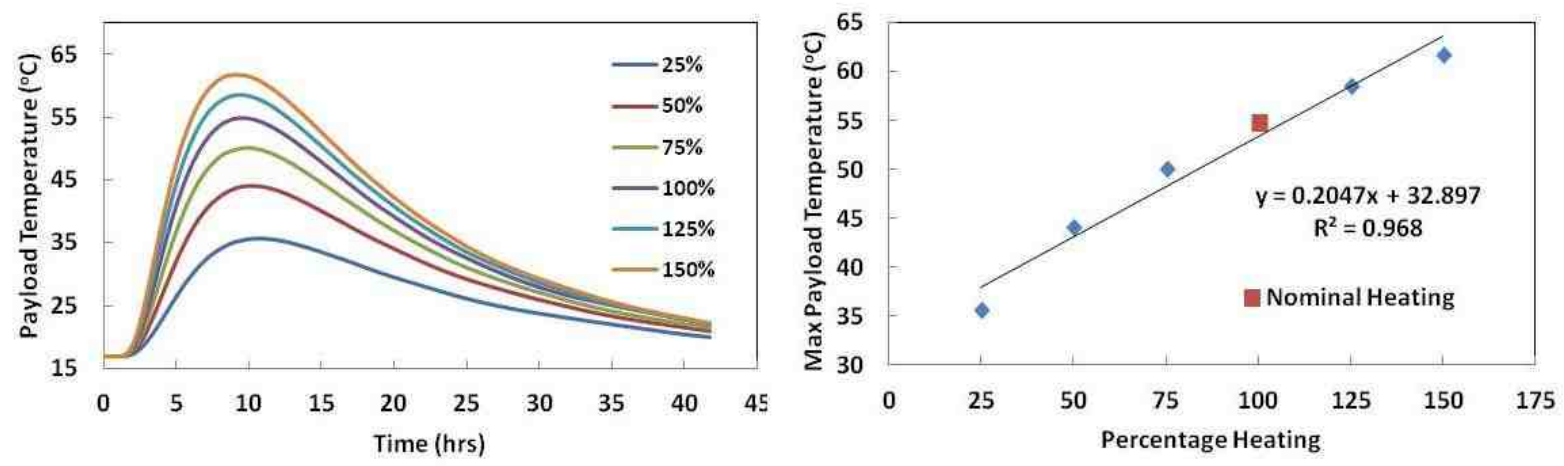

Figure 17. Parametric studies for heat flux magnitude variation for the high heat load trajectory. 

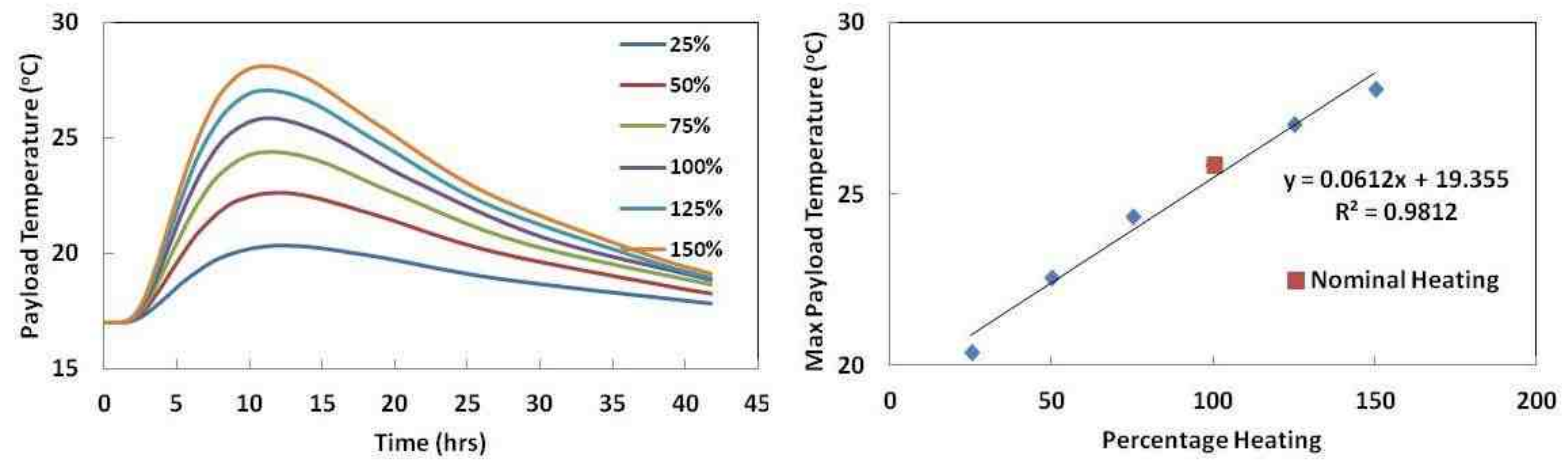

Figure 18. Parametric studies for heat flux magnitude variation for the low heat load trajectory.

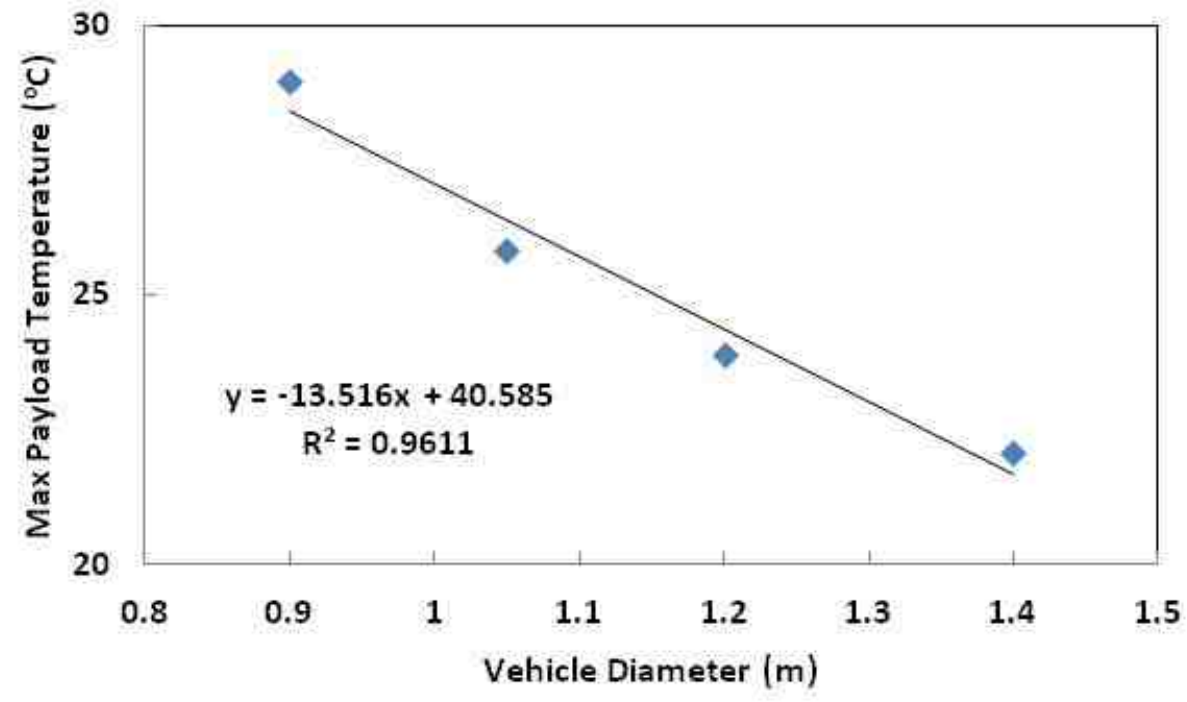

Figure 19. Comparison of peak payload container temperature for various vehicle diameters.

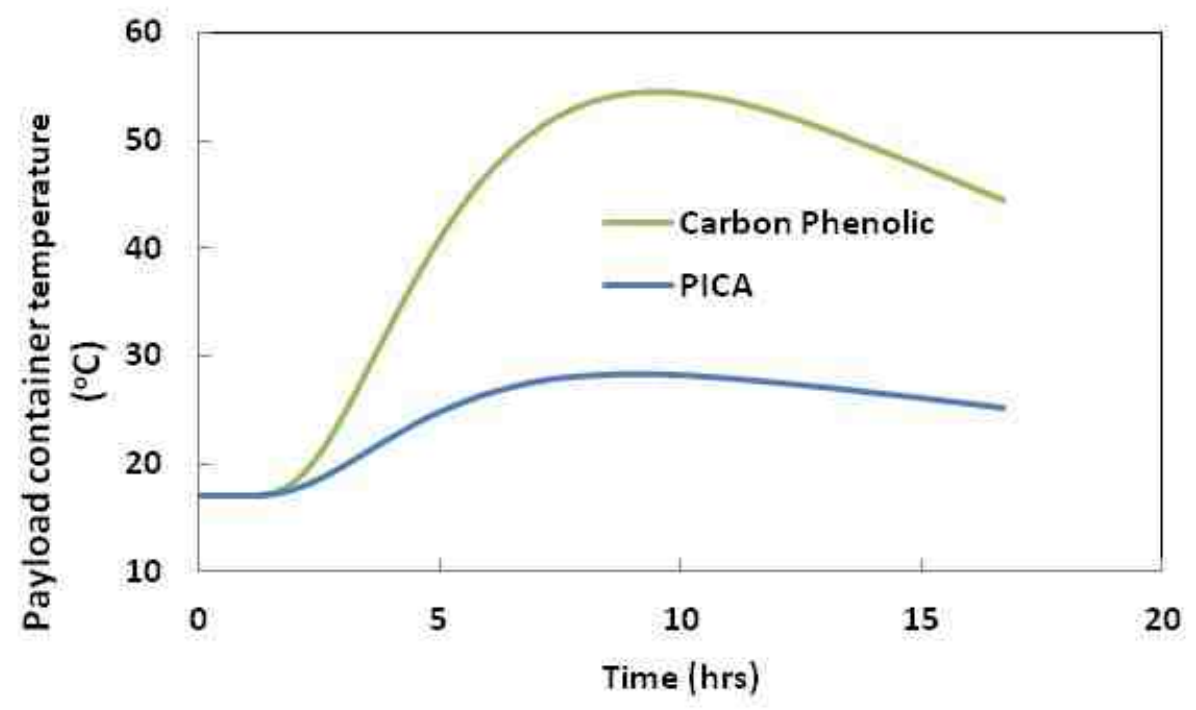

Figure 20. Comparison of payload temperature for different TPS material. 


\section{Summary and Conclusions}

A finite element thermal soak model was developed for a MSR-based geometry. Preliminary thermal soak analyses were performed for different trajectories to study the temperature rise inside the vehicle. CFD analysis was conducted to generate aerothermal environment for the entire vehicle including fore and aft bodies for both high and low heat load trajectories. The temperature histories on the foam and payload were obtained by conducting FE thermal analysis for theses trajectories and compared with each other. The data show that the magnitude of total heat load to the vehicle influences the peak payload temperature, and it will be useful to include thermal soak requirement while sizing the TPS thickness for the vehicle to ensure low payload temperature after the touchdown. Parametric studies were performed by varying heat flux magnitude, vehicle diameter, and TPS materials. The results suggest that linear relationships can be established for some of the variables to develop a low fidelity thermal soak model.

In the near future, several parametric thermal soak analyses will be performed for the five representative trajectories that will encompass the MMEEV mission trade space for sample return. Correlation coefficients will be subsequently developed based on theses analysis to establish a thermal soak model in the MSAPE tool.

\section{Appendix}

Table 2. Specific heat capacity of Rohacell-51.

\begin{tabular}{|c|c|}
\hline Temperature & $\begin{array}{c}\text { Specific Heat } \\
\text { Capacity } \\
\text { (Cp) }\end{array}$ \\
\hline$(\mathrm{K})$ & $(\mathrm{J} / \mathrm{kg}-\mathrm{K})$ \\
\hline 0.00 & 2399.04 \\
\hline 320.56 & 2399.04 \\
\hline 340.33 & 2687.93 \\
\hline 360.33 & 2394.85 \\
\hline 380.33 & 1896.62 \\
\hline 400.33 & 1565.86 \\
\hline 420.33 & 1423.51 \\
\hline 440.33 & 1394.20 \\
\hline 460.33 & 1193.24 \\
\hline 666.67 & 1193.24 \\
\hline
\end{tabular}

Table 3. Thermal conductivity of Rohacell-51.

\begin{tabular}{|c|c|}
\hline Temperature & $\begin{array}{c}\text { Thermal } \\
\text { Conductivity }\end{array}$ \\
\hline$(\mathrm{K})$ & $(\mathrm{W} / \mathrm{m}-\mathrm{K})$ \\
\hline 95.83 & 0.0127 \\
\hline 134.94 & 0.0171 \\
\hline 154.72 & 0.0190 \\
\hline 174.44 & 0.0208 \\
\hline 228.89 & 0.0272 \\
\hline 288.33 & 0.0360 \\
\hline 367.22 & 0.0567 \\
\hline 479.44 & 0.0848 \\
\hline 666.67 & 0.0848 \\
\hline
\end{tabular}

\section{Acknowledgments}

This work was supported by the In-Space Propulsion Technology Program and by NASA STRAD contract no. NNA10DE12C to ERC, Incorporated. The authors would like to acknowledge student intern John Pham for creating some of the plots. Support of Michelle Munk, Lou Glaab, Robert Maddock and Anjie Baker from Langley Research Center and Jim Arnold, Tom Squire and Kerry Zarchi from Ames Research Center is also appreciated.

\section{References}

${ }^{1}$ Agrawal, P., Prabhu, D.K. and Chen Y-K, “Thermal Analysis of Small Re-entry Probes," AIAA 2012-0219, Jan. 2012.

${ }^{2}$ Maddock, R. W., et. al., "Multi Mission Earth Entry Vehicle Design Trade Space and Concept Development Status," proceedings, $7^{\text {th }}$ International Planetary Probe Workshop, Barcelona, Spain,14-18 June 2010. 
${ }^{3}$ Samarah J.A., Maddock R. W. and Winski R.G., "An Integrated Tool for System Analysis of Sample Return Vehicle," proceedings, 2012 IEEE Aerospace Conference, Big Sky, Montana, March 3-10, 2012.

${ }^{4}$ Maddock, R. W., et. al., "Multi-Mission Earth Entry Vehicle Design Trade Space and Concept Development Strategy," proceedings, $\sigma^{\text {th }}$ International Planetary Probe Workshop, Atlanta, Gorgia, June 2008.

${ }^{5}$ Amundsen R.M., Dec J.A., Mitcheltree R.A., Lindel M.C., Dillman R.A., "Preliminary Analysis of a Mars Sample Return Earth Entry Vehicle," AIAA 2000-2584, June 2000.

${ }^{6}$ Chen, Y.-K., and Milos, F. S., "Fully Implicit Ablation and Thermal Analysis Program (FIAT)," Journal of Spacecraft and Rockets, Vol. 36, No. 3, pp 475-483.

${ }^{7}$ Chen, Y.-K., and Milos, F. S., "Thermal Response Modeling System For a Mars Sample Return Vehicle," proceedings, Thermal \& Fluids Analysis Workshop, Huntsville, Alabama, September 10-14, 2001.

${ }^{8}$ MSC Software Corporation, Marc Version 2008r1, 2 MacArthur Place, Santa Ana, CA 92707.

${ }^{9}$ Felman J. et. al., "Material Properties of PICA”, NASA TM-2010-216399, June 2010.

${ }^{10}$ Britt S. "Mechanical and Thermal Testing of ENKA Rayon Based MX4926 Carbon Cloth Phenolic," Southern Research Institute, Rept. SRI-ENG-06-37-11610.01, August 2006.

${ }^{11}$ MIL-HNBK-5J, "Metallic Materials and Elements for Aerospace Vehicle Structures," IHS publication, Jan. 2003.

${ }^{12}$ Wright, M., Candler, G., and Bose, D., "Data-Parallel Line Relaxation Method for the Navier-Stokes Equations," AIAA Journal, Vol. 36, No. 9, 1998, pp. 1603-1609. 